\title{
Conference Management Application in Salesforce
}

\author{
Gayathri.G ${ }^{1}$, Arulmozhi.M ${ }^{2}$ \\ Assistant Professor, Department of Computer Science, \\ Ponnaiyah Ramajayam Institute of Science and Technology PRIST University, Thanjavur ${ }^{1}$ \\ M.C.A., Scholar Department of Computer Science, \\ Ponnaiyah Ramajayam Institute of Science and Technology PRIST University, Thanjavur ${ }^{2}$
}

\begin{abstract}
Salesforce is a CRM Platform provides various software solutions and help administrators and designers to improve and hand out routine software. Salesforce.com is based on multi-tenant architecture. This means that several clients part common technology and all run on the latest release. We don't have to worry about the application or infrastructure upgrades - they happen automatically. This helps your institute emphasis on modernization rather than managing technology. In this project we are Building a app that lets conference attendees to view the session schedule, and absorb more about conferences and speakers. we are Creating a data model for a conference management application using Apex classes and work with the Sales force Object Query Language (SOQL) to implement the business logic of the application, such as making sure speakers are not double-booked.
\end{abstract}

Keywords: Salesforce Object Query Language (SOQL), National Institute of Standards and Technology (NIST)

\section{INTRODUCTION}

$>$ This project entitled as "Conference Management Application In Salesforce" has been developed using with cloud computing.

$>$ Salesforce is a CRM Platform provides various software solutions and help administrators and designers to advance and allocate custom software. Salesforce.com is built on multi-tenant design.

$>$ This means that several customers segment shared technology and all run on the modern release. We don't have to worry about the application or infrastructure upgrades - they happen automatically. This services your association effort on modernization rather than managing technology.

$>$ Also we are Creating Lightning components using Base Lightning components and use these components to create and edit records. Also we create and execute a batch process to send reminder emails to the conference speakers.

$>$ Bank of cloud computing is defined by the National Institute of Standards and Technology (NIST) as "a classical for allowing convenient, on-demand network contact to a common pool of configurable computing assets (e.g., networks, servers, storing, presentations, and service area)

> That can be quickly provisioned and out with negligible administration effort or platform provider interaction." (Brown 2011). NIST identifies five essential characteristics of cloud computing: on-demand service, expansive network entree, resource pooling, rapid elasticity, and measured service.

$>$ Cloud computing can be arranged in altered ways, each of which affords separate trade-offs for administrations which are peripatetic applications to a cloud location.

NIST defines the cloud deployment models as follows:

Private cloud: Only an organization uses the cloud infrastructure.

$>$ It may be accomplished by the suggestion or a third gaiety and may exist on substance or off statement.

$>$ Community cloud: Several administrations part the cloud organization and supports a thorough community that has shared anxieties (e.g., duty, safety requirements, strategy, and submission contemplations).One of the administrations or a third party may manage the cloud and may happen on statement or off statement.

$>$ Communal cloud: The cloud organization is made accessible to the communal or a huge industry group and is owned and managed by an organization selling cloud services.

$>$ Hybrid cloud: The cloud infrastructure is a composition of two or more cloud(private, municipal, or community) that continue exclusive beings but are assured together by uniform or exclusive technology that assists data and presentation portability (e.g. cloud overflowing for capacity-paired between clouds). 
Vol. 8, Issue 3, March 2019

$>$ Salesforce is the world's \#1 customer relationship management (CRM) platform. Our cloudbased, CRM applications for sales, service, marketing, and more don't require IT experts to set up or managesimply log in and start connecting to customers in a whole new way.

$>$ cloud stands and presentations, the company is greatest known for its Salesforce client association administration $(\mathrm{CRM})$ creation, which is collected of Sales Cloud, Service Cloud, Marketing Cloud, Commerce Cloud, Analytics Cloud, IoT Cloud, App Cloud, Health Cloud, Financial Services Cloud, Force.com, and Chatter.

$>$ Salesforce Sales Cloud manages contact information and integrates social media and real-time client association through Conversation. It maintenances deals, publicizing and customer maintenance in both B2B and B2C backgrounds. Sales Cloud helps path client info and connections in one place, systematizes multipart business processes, keeps all info up to date, encourages leads and tracks the effectiveness of marketing campaigns.

\section{PROBLEM STATEMENT}

\subsection{Existing System}

$>$ Several companies using Salesforce need integration with their present system for continuous assignment of data.

$>$ If you don't want to type your data twice into multiply systems, then Salesforce integration is your purpose. We proposal 2 types of integration purpose.

a. Actual time integration

b. Group mode integration.

In actual mode integration, our solution is a custom salesforce unit or app which would reside on salesforce and automatically synchronize the data to any external system real time. In batch mode integration, our solution would synchronize sales force data with exterior systems routinely at consistent intervals.

\section{Disadvantages}

$>$ Our solution also has a web built front end view which would allow you to view the status of the connections and afford you 3 dimensional view of the data.

\subsection{Proposed System}

Salesforce is the world's leading customer relationship management (CRM) platform. The company's cloudbased applications for sales, service, marketing, and more enable users to start concerning with clienteles in new ways. $>\quad$ Now combined, the Salesforce cloud and D-Tools System Integrator help users reorganize operations, systematize processes and develop operational efficacies. Not only does this provide active visibility and liability, It allows project managers to better manage budgets, sales teams to improve opportunity wins, and financial teams to more accurately track revenue and expenses - all using powerfully integrated applications.

\section{Advantages \\ $>\quad$ Easily conform the session speaker \\ $>\quad$ Reject double booking confirmation \\ $>\quad$ Sending confirmation email \\ $>\quad$ Send final reminder email}

\section{ARCHITECTURE DIAGRAM}

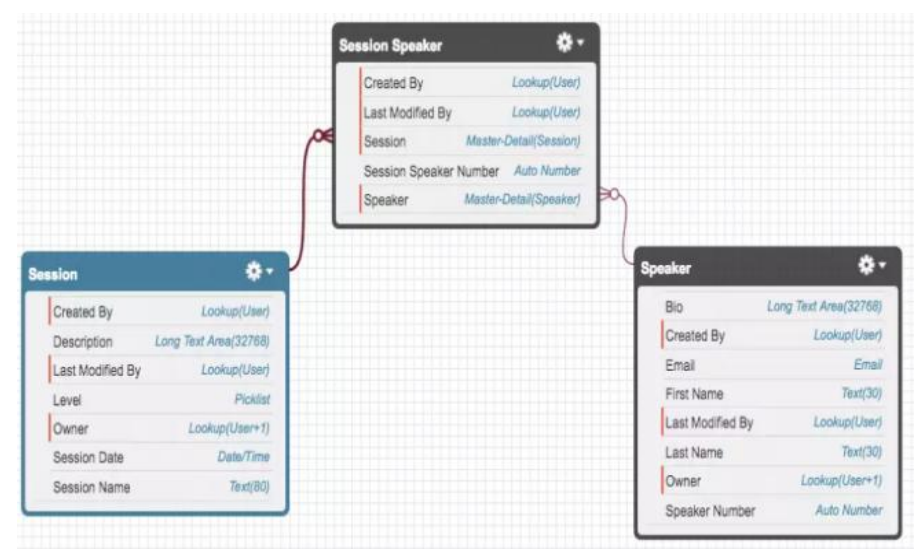




\section{CONFERENCE SESSION SPEAKER}

\section{SESSION}

$>$ A huge meeting will usually be called a conference, while a minor is termed a workspace.

$>$ They influence be single track or several track, where the earlier has only one session at a time, while a various track meeting has several equivalent sessions with speakers in discrete rooms speaking at the identical time.

\subsection{The Importance of The Session Title:}

$>$ The session title is the first, and maybe only, impress you make on a probable attendee.

$>$ On average, eight out of ten will read the session title, but only two available of ten will read the session description and leaner objectives.

$>$ So it's fairly obvious that if people stop at the title, you're already dead in the water. Without a convincing capacity that turns a browser into a bibliophile, the rest of your words may as well not even exist.

$>$ So, from a performance situation, writing a excessive session title is a serious skill. The Four "Us" Attitude To Script Titles The American Authors \& Artists trainers teach

\subsection{Four Conference Session Practices that Matter:}

Come up with a good, intriguing session title:

$>$ It's the first and perhaps only impression you'll make on a potential attendee. The principal determination of a title is to get the attendee to read the first stretch of the report.

\subsection{Liven Up Your Session Description:}

$>$ Most conference session descriptions are gray, important attendees to trust that the management will be the same.

$>$ Concentration on the reader. Make a promise and address the WIIFM benefits of the presentation.

$>$ The word restrictions forced on most session reports is not the challenge. It's choosing the right words to accurately describe the session, pull readers in and get them to commit to attending the session.

\subsection{Craft Strong Learner Objectives:}

$>$ These declarations that follow the session report describe what the contestant is expected to achieve (outcomes) as result of attending.

> Strong LOs have three distinguishing characteristics:

- observable

- measurable (you can evaluate them immediately upon leaving the session) and

- actively done by the participant.

\subsection{Spell Out Who Should Attend Both By Group And Experience Level:}

$>$ This is a critical component that should be built-in in conference marketing ingredients.

$>$ Several attendees have walked out of a session and said, "That workshop was not for me. I wish the session report had been more detailed.

$>$ Occurrence authorities should also label the suitable viewers for each session in terms of skill level novice, in between, veteran - and niche area (as well as other categories specific to each industry).

\section{CONFERENCE SPEAKER}

$>$ Essential a topmost conference speaker for your next commercial event, meeting, or conference. Research shows that the best conference speakers can shed invaluable insight on your company's goals, pain points, and focuses.

$>$ Also, conference speakers are trained at collecting up each unique viewers to motivate, employ, authorize, and, of course, motivate your team for results such as increased productivity, improved employee morale, higher sales, game-changing innovation, or more effective communication.

\subsection{Business Speakers:}

$>$ Business speakers are best suited to transform your association .Our team of powerful, impactful speakers contains CEOs and influential, depositors, successful industrialists and more, all with a passion for transforming businesses.

$>$ Next 20 years and thousands of schedules, BigSpeak is the professional on business speakers. We first learn your company's objectives, viewers composition, and investment level, and then we contest it to the best business speaker applicants for your thought. 
$>$ When you're ready to think big, or think outside the "boss", bring one of our top business speakers to your organization. Then, ask us about how you can go elsewhere the keynote with teaching to lock in the knowledge with our custom-tailored training programs.

\subsection{Keynote Speakers:}

$>$ Keynote Speakers, Business Speakers and Motivational Speakers - use examine screens below to find the best keynote speakers and create adapted MyCatalogs.

$>$ Exploration here for the best business speakers, personality speakers, and keynote speakers at the full facility speakers department with top client fulfillment.

\section{CONFERENCE BOOKING CONFIRMATION}

\subsection{Booking Confirmation:}

Identical though a meeting is on the agenda it would help everyone in your office to identify if a meeting is likely to static occur. With Robin, you have an prospect to authorize (or delete) the meeting soon before it starts thanks to in-app reminders and display cues.

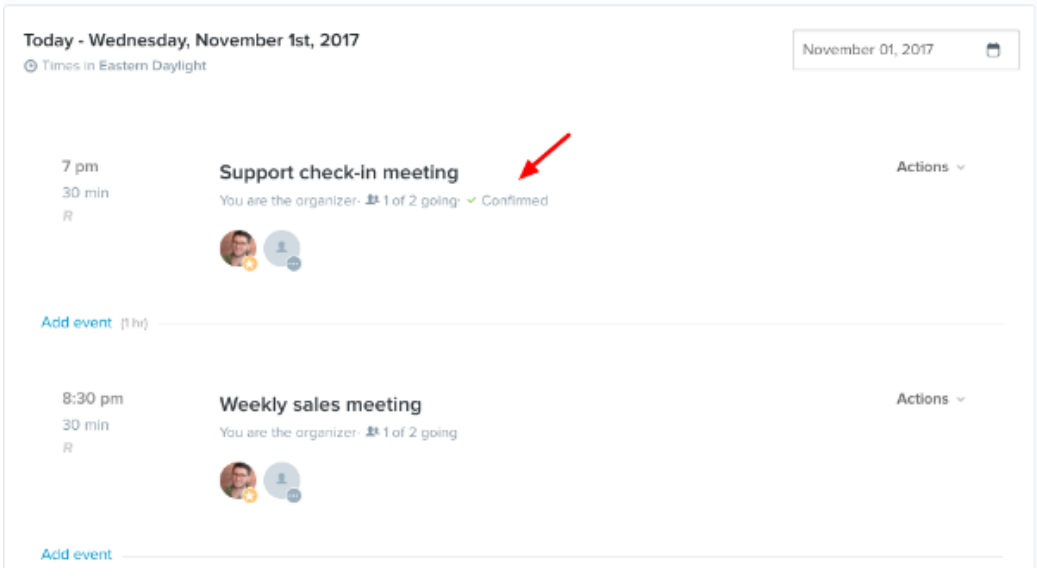

\subsection{Confirmation Email:}

$>$ The person registering for the conference will receive a confirmation email with a link to edit the conference registration.

$>$ The confirmation will include material for the registrant and all of the visitors. The Registrant's Email with commerce will include the following by default.

$>$ There will be opening redundancy hire the email recipient know that they have itemized for the occasion.

\subsection{Conference Details :}

The Conference Name, Date, Time, and Session field will be displayed.

\subsection{Registrant Information:}

Registration specifics appeal in the name of the Registrant step as the main header, the main registrant's name as the sub-header and the grounds that happen on the registrant step.

\subsection{Guest Information:}

- Guest details pull in the name of the Guest step as the main header, the Guest's name as the sub- header and the fields that exist on the guest step.

$>$ If the event is set up to collect guests or the primary registrant didn't add any guest, this section will not display.

\subsection{Activity Details:}

$>$ All activities with the Activity Name, Date, Time and Session name, Level, will be displayed with each registrant listed below.

$>$ If the event is set up not to include activities or the primary registrant didn't select to attend any activities, this section will not display.

$>$ The activities and the categories appear in the the confirmation email in the order they appear on the Conference Form. 
Vol. 8, Issue 3, March 2019

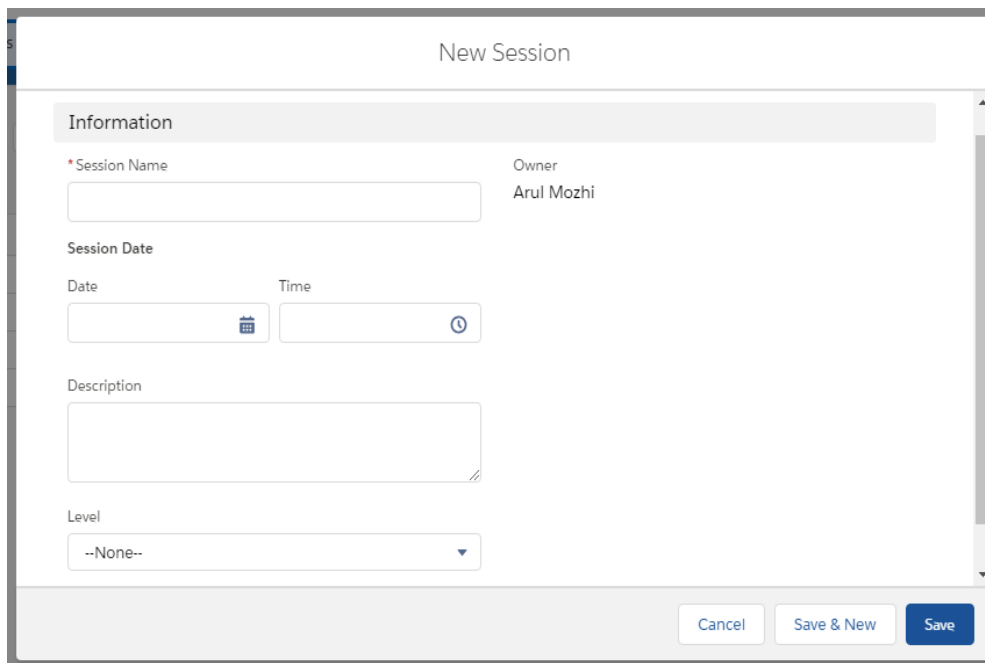

VII. CONCLUSION

> Technology has made a massive change to the conference industry. Apps for phones are designed so the public can get details on upcoming and on going conference Greenwell, Danzey-Bussell and Shonk (2013)

$>$ Suggests Twitter, Youtube and Foursquare are now used to promote and market many conference. As new technologies emerge, marketers will continue to reach out to new consumers through these new mediums.

$>$ Conference management application face challeges in planning, organization, institute and technology, easily $u$ can know the conference session and session_speaker and also avoid the reject double booking, sending the email confirmation for session speaker....we are using comfortable for this application all are using in Salesforce technology in world no.1 CRM.

\section{REFERENCES}

[1]. The Economist (2009), "Cloud Computing: Clash of the clouds". http://www.economist.com/displaystory.cfm?story_id =14 637206

[2]. Andersson. H, Moe, G. \& Wong, L.A (2011), "Data center goes lean", McKinsey Journal, March.

[3]. Asava, R \& Mzee, H. (2010), "Cloud Computing meets Project Management”, PM World Today - June (Vol XII, Issue VI)

[4]. Barbero, M.C. \& Copetti, G. (2010), "The PMO as a centre of excellence [electronic resource] :

[5]. virtual community or physical unit?”, PMI Global Congress 2010--EMEA. Proceedings.

[6]. Brown, E. (2011), Final Version of NIST Cloud Computing Definition Published, NIST Tech Beat: October 25

[7]. Gartner (2008), "Economies of Scale Are the Key to Cloud Computing Benefits", Gartner, June.

[8]. Gartner (2008b) "Cloud Computing: Defining and Describing an Emerging Phenomenon", Gartner, June 2008

[9]. Nicoletti. B. (2010a), "Lean and Digitize Project Management", IPMA 24th Congress, Istanbul, Turkey.

[10]. Nicoletti. B. (2010b), "Gli Strumenti del Lean and Digitize", Milan: FrancoAngeli.

[11]. Nicoletti. B. (2012), "The Lean and Digitize Method", London: Gower Publishing. 